\title{
New Books About the Book Arts
}

Die Erfindung des Buchdrucks als technisches Phänomen. By Friedrich Adolf SchmidtKünsemüller. (Kleiner Druck der Gutenberg-Gesellschaft No. 48). Mainz, Gutenberg Society, 1951. 124 p. Free to members.

The Dream of Poliphilo. Related and interpreted by Linda Fierz-David. Translated by Mary Hottinger. (Bollingen Series XXV). New York, Pantheon (1950). 244 p., 34 illus. \$3.50.

The Hieroglyphics of Horapollo. Translated by George Boas. (Bollingen Series XXIII). New York, Pantheon (1950). 134 p., Io illus. $\$ 3.50$.

The Art of Botanical Illustration. By Wilfrid Blunt, with the assistance of William T. Stearn. New York, Charles Scribner's Sons; London, William Collins Sons, 195I. 304 p., 46 color plates, 32 plates in black and white, 61 text illus. $\$ 5.00$.

Die Botanische Buchillustration. Ihre Geschichte und Bibliographie. By Claus Nissen. Volume I: History. Volume II: Bibliography. Issued in parts. Stuttgart, Hiersemann, 1950-Not complete.

Baroque Book Illustration. A Short Survey. From the collection in the Department of Graphic Arts, Harvard College Library. By Philip Hofer. Cambridge, Harvard University Press, 1951. 43 p., 149 illus. $\$ 7.50$.

Designing Books. By Jan Tschichold. New York, Wittenborn, Schultz, Inc. (I95I). 21 p., 58 plates. $\$ 5.00$.

The books discussed in the following review have been selected because each of them in its own way makes a valuable contribution. Each of them has something new to say to the librarian who is interested in books not merely as a vehicle of information but as the tangible, physical manifestation of spiritual, intellectual and artistic endeavour.

The first of these books, recently distributed to the members of the Gutenberg Society, has perhaps a more specialized appeal than most of the others in this group. It deals with the technical aspects of the invention of printing with movable type. It is a serious and sober discussion, deliberately stressing the practical, mechanical side of early printing at the expense of historic and cultural factors. The usefulness of the book lies in this concentration. Based upon careful scrutiny of surviving monuments and documents and an equally careful analysis of the vast and evergrowing literature on early printing, it is a contribution of considerable value. The author is not committed to any dogma or to the defense of a particular historic tradition. For this reason one finds here a quite impartial and thorough review of the several technical experiments that were carried on not only in Strassburg and Mainz, but elsewhere in Europe as well. Against this background Gutenberg's contribution is shown as precisely as is possible with the information available today.

The next five books on our list, all in fact except the last item, have one thing in common: They all bring new and sometimes startling insight into the role of the book in what might be called the great centuries of Renaissance culture in Europe between 1500 and 1800. This is all the more surprising since many observers agree that this period has been quite thoroughly explored from many points of view.

The Hypnerotomachia Poliphilo of Francesco Colonna, for instance, is known to every lover of fine books as the most perfect realization of the ideal of beauty and harmony in Italian Renaissance printing. Yet, hardly anyone knows what this book is really about, what it meant to the Italians and the Frenchmen who read it and gazed at its pictures so eagerly in the 16 th and 17 th centuries, and what it still means today. Linda Fierz-David deserves the gratitude of modern readers for having unlocked a hitherto secret treasury, of beauty and imagination. Those of us who have an interest in the exploration of the subconscious mind, whether by means of the visual arts, through literature or scientific analysis, will be able to enjoy the skilful résumé and the ingenious interpretations which form the main body of this study. Those, on the other hand, who are interested in Renaissance culture and the means of its projection, will be interested to find how "modern" was the outlook of this Dominican monk, Francesco Colonna, how closely linked is his imagery and literary intent with progressive cultural manifestations which have meaning to people in the twentieth century. This relationship is by no means 
apparent on the surface, it becomes clear only after an understanding has been gained of the substance of this work and of the elements which are blended in one in the Hypnerotomachia: "the humanistic conception of the revival of classical culture, the courtly conception of the love of women as a task; the alchemical conception of the transmutation of matter." The dream experiences of the hero of this I5th century novel (he is taught to free himself from his obsession with alchemy and medieval courtly love through identification with humanistic culture) are bound up with a specific historic situation in the development of the western intellect; but their literary and pictorial condensation in a great book is of more than historical interest, They convey a sense of oneness in man's struggle to conquer the perplexities and riddles of human existence.

The question of whether the artist should speak only of matters of the broadest public interest and in a realistic idiom immediately comprehensible to every member of a given society, or whether he has the right to choose his message and to communicate it by whatever means he believes to be most effectivethis question has become a vital issue in the conflict between totalitarian and democratic society.

The Hypnerotomachia is an outstanding example of the use of symbolism in a crucial moment in the development of the western mind. We are beginning to understand that it was not an isolated instance. On the contrary, the employment of graphic images with hidden, symbolic meaning, discovered or rediscovered in the Renaissance, became a main strand in its cultural fabric. At the very moment when man set about to discover and record vast new strata of the physical universe with highly rational methods, it was felt keenly by many that truth was elusive, and that its evanescent spirit could often be reflected more faithfully in the allusive, hidden image. George Boas' translation of The Hieroglyphics of Horapollo is an important study of a curious book which has had remarkable influence in the establishment of literary and pictorial images and emblems. It was written in the Egyptian language by Horapollo Millacus and later translated into Greek by one "Philip." The author of the new translation, who is a professor at Johns Hopkins University, describes himself as an
"Iconologist," interested in images as an historian of ideas and of taste. It was as part of the rebirth of platonism that Horapollo caught the imagination of humanist leaders. Willibald Pirkheimer in Nuremberg made a translation into Latin and his friend Dürer drew some marvellous illustrations which Professor Boas reproduces with his English rendering, without however tracing their possible relationship to illustrations in the printed editions of this book.

The rational, naturalistic approach to the recording of the world around us can perhaps best be studied in the history of botanical illustration. Two recent books of European origin deal with this important form of documentary illustration. They show how plant portraits produced in the last two thousand years were not primarily symbolic or individual interpretations, but successive attempts at objective realism. These two books also demonstrate that especially during the great historic age of European bookmaking botanical artists and their engravers and printerpublishers produced breathtakingly beautiful interpretations of plant life. Many of these efforts, not hitherto recognized, belong among the masterpieces of the high art of bookmaking.

As I said in a recent article in Publishers' Weekly (Nov. 3, 1951), Wilfrid Blunt's The Art of Botanical Illustration is that rare and delightful thing, a work of scholarship which is also a work of art. The other book, Dr. Claus Nissen's Die Botanische Buchillustration, is the result of many years of painstaking research by a librarian-bibliographer who is also a trained natural scientist. Both books do full justice to the great age of printed botanical illustration, but they also include surveys of the classical and medieval manuscripts which precede the first printed herbals. They also bring the story to the present time. In the later development, England's share is justly given the place of honor, but the contribution of other countries and the rapidly changing methods of technical reproduction is traced, especially in Dr. Nissen's systematic and comprehensive coverage.

Both these books have one particular value for those librarians who have in their care important collections of books printed before the middle of the nineteenth century: they can be used as guides to the discovery and reevaluation of scarcely appreciated or perhaps 
completely neglected masterpieces in these very collections.

This is true to an even greater extent, though of course for one particular period only, of Baroque Book Illustration. In this study Philip Hofer, in charge of the Harvard Library's Department of Graphic Arts, set himself the task of demonstrating that the contribution of the seventeenth century to the arts of the book has been seriously underestimated by almost every authority in the field. There can be little doubt that this claim is justified and that he has produced sufficient evidence to prove this point. The book is based on the author's own collection of about one thousand books of the baroque period, the only systematic attempt to select significant examples from a vast stream of production which has baffled many students by its contradictory stylistic trends and the bewildering variety of its intentions. Philip Hofer emphasizes in his introduction "the sweeping range of emotional content, from religious ecstasy all the way to the most severe self-restraint," which one could also describe as a curious capacity for combining highly imaginative symbolism with the most objective documentation.

The study of the I 49 illustrations, superbly reproduced by the Meriden Gravure Company, is an absorbing and richly rewarding experience. Surprisingly few of the books from which these plates were selected have previously been exhibited, described or commented upon. Many of them record contemporary events, especially celebrations and ceremonies of the great rulers of a world in the throes of violent conflict, with brilliant freshness of observation. The architectural and the theatrical tendencies of Baroque illustration are well documented in the plates and commented upon in the introduction. The broad political background of the period and the social forces which sought expression in these monumental graphic arts productions are traced briefly, but with a keen sense for the significant and the essential. The special conditions prevailing in each of the countries which saw important work performed, are described in a series of all-too-short chapters, each devoted to one country or geographical unit.

The book leaves many questions unanswered. Frequently the plates suggest questions of interpretation and evaluation for which there was no room in the brief descriptions of the reproductions. An adequate answer to such problems would be possible only within the framework of a broad analytical approach to the nature of Baroque illustration. This, however, lay outside the intentions of this work which was planned to serve as a first brief introduction to an unjustly neglected, fascinating field of study. One hopes that the full catalog of the Baroque books in the Harvard collection, which Philip Hofer is now preparing, will offer an opportunity for a further development of many themes which have first been alluded to in the present study. One also hopes for bibliographical references to the studies about some of the artists, printers and patrons of this period which have already been published. There is no one better suited for these important tasks than the author of the present volume.

The interest to librarians of the last item on our list, Jan Tschichold's Designing Books, is quite different from the other books reviewed here. This book of one of Europe's most talented and also most articulate book designers is directed mainly to practicing typographers. It is a collection of 58 strikingly beautiful examples of title pages, covers and text pages, distinguished through their remarkable restraint. The art of attaining maximum effects through a minimum of means is demonstrated here with great refinement and mastership. The reproductions are preceded by a brief and simple instruction on how to design a book, followed by what might be described as a "code of fair composition," also brief and simple.

Jan Tschichold's typographic creed is perhaps best demonstrated in his insistence that "first of all a book should display good taste, not what is commonly called personality. Tact, restraint, the conviction that one is subservient to the book and can add something to its appreciation by means of a really pleasing, enjoyable, elegant, practical, even beautiful presentation-these are the true qualifications of a true typographer."

And the librarian? In the bewildering onslaught of sharply competing media, his faith in the book as a central medium of culture, if indeed he holds such a belief, is sharply challenged. Within the realm of the book itself he witnesses the passing of traditional typographic standards. Photographic composition, 
offset printing, mass production of cheap reprints, a shift from verbal to pictorial presentation, all these factors seem to spell the doom of the typographic art as a valid expression of intellectual content.

Jan Tschichold's Designing Books is a vivid demonstration of the kind of values we stand to lose if we surrender thoughtlessly and without a struggle to forces primarily motivated by efficiency demands and economics. That is one important function of this book. From this follows another one: The loss of these standards is by no means a matter of inevitable necessity. The task of meeting the cultural challenge of mass production lies still much more before than behind us. Such books as Jan Tschichold's are important yardsticks of quality against quantity. Above all, they demonstrate the values that may very well prove capable of transfer or redefinition in mass production, if enough people believe that such a thing is not unimportant. This is a question in which the vote of the library profession carries a great deal of weight.-Hellmut Lehmann-Haupt, New School for Social Research.

\section{Library Practice Abroad}

\section{Biblioteksprob'em; några synpunkter på bib'io-} teksarbetets organisation och rationalisering. Ed. by Valter Ahlstedt, Knut Knutsson, Folke Löfgren. Stockholm, Natur och Kulter, 1952. 172p. Sw. Kr. 8.25.

The Bibliotekstekniska Klubben is a group founded in Stockholm in 1943 to bring into open discussion some of the more urgent problems of modern librarianship. The present volume contains six essays, five by Swedish librarians and one by a Danish librarian, which were presented to the club. Four of the contributors are members of the staff of the Stockholm Public Library; and all three of the editors, including head librarian Knut Knutsson, are officers of the same library. There are English summaries of each of the essays on p. 167-172.

The first three essays deal with problems of cataloging and classification. Valter Ahlstedt, an amanuensis at the Stockholm Public Library, writes on "Enhetskatalogisering" ("uniform cataloging" rather than "unit cataloging," as defined in the English summary). Ahlstedt argues for intrinsic uniformity based on the three main functions of the catalog (entry, description, and location). He frowns on the stern rigidity of codes such as the Anglo-American and the Prussian Instruktion, the two most influential, which enforce uniformity rather than encourage it. In his essay on "The Relations between Cataloging and Administration" E. Allerslev Jensen, an inspector in the Danish Directorate of State Libraries, reviews some of the American discusions of cataloging problems during the last decade and studies their applicability to the Scandinavian scene. He argues for simplified inter-Scandinavian cataloging rules with printed cards issued coordinately with the national bibliography (precisely what was started within the last year by the Deutsche Bibliothek at Frankfurt am Main). His contention that cataloging as a technique is subordinate to the basic purposes of the library represents a refreshing viewpoint.

Carl Björkbom, librarian of the Royal Technological University in Stockholm, contributes a study of "Principles of Bibliographical Classification" in which he expounds the virtues of a "synthetic classificatory language" as opposed to natural language. He uses the Decimal Classification as the point of departure for his discussion. He points out that classification is not to be viewed primarily as a scheme for arrangement of books on the shelves but rather as a device for the codification of knowledge (thus making it an indispensable tool in the mechanization of bibliography).

Folke Löfgren, "first librarian" at the Stockholm Public Library, reports on the result of job analysis and work measurement at his library, an operation which resulted in substantial reassignment of clerical and professional duties through reduction of the professional staff and expansion of the clerical staff.

Pertrus Jonsson, an amanuensis at the Stockholm Public Library, examines the peculiarly Scandinavian problem of satisfying the claims of creative writers for a certain subsidy based on the circulation of their books in public libraries. ("The Library Fee Question" is a somewhat misleading translation in the English summary.) In Denmark and Norway creative writers receive a subsidy based on the circulation of their books in public libraries; and while the Swedish Writers' Guild has made similar demands, Jonsson rejects them for an alternative pro- 